\title{
Aydın ilinde yetiştirilen ticari çilek çeşitlerinin fiziksel, kimyasal, biyoaktif ve aroma özellikleri
}

\section{Physical, chemical, bioactive and aroma properties of commercial strawberry cultivars grown in Aydın province}

\author{
Ahmet GÖRGÜÇ ${ }^{1}$ iD Aslı YILDIRIM $^{1}$ iD, Dilara KONUK TAKMA ${ }^{1}$ iD, Edibe Seda ERTEN $^{1}$ iD, \\ Fatih Mehmet YILMAZ $^{1 * \text { iD }}$ \\ ${ }^{1}$ Aydın Adnan Menderes Üniversitesi, Mühendislik Fakültesi, Gıda Mühendisliği Bölümü, 09010, Efeler, Aydın
}

To cite this article:

Görgüç, A., Yıldırım, A., Erten, E., Takma, D. \&

Yılmaz, F. (2019). Aydın ilinde yetiştirilen ticari çilek çeşitlerinin fiziksel, kimyasal, biyoaktif ve aroma özellikleri. Harran Tarım ve Gıda Bilimleri Dergisi, 23(2): 131-141. DOI:

10.29050/harranziraat.466720

Address for Correspondence: Fatih Mehmet YILMAZ e-mail:

fatih.yilmaz@adu.edu.tr

Received Date: 02.10 .2018

Accepted Date: 14.03.2019

(C) Copyright 2018 by Harran University Faculty of Agriculture. Available on-line at www.dergipark.gov.tr/harranziraat
Öz

Aydın ili, çilek yetiştiriciliğinde ve ihracatında ülkemizde Mersin'den sonra ikinci sıradadır. Bu çalışma kapsamında, Aydın sınırları içerisinde yoğun şekilde yetiştiriciliği yapılan ve en çok ihracatı gerçekleştirilen ticari çilek çeşitlerinin fiziksel, kimyasal, biyoaktif ve aroma özellikleri belirlenmiştir. Bu kapsamda, ticari hasat olgunluğundaki Florida fortuna, Rubygem ve Sabrina çilek çeşitlerine toplam kuru madde, $\mathrm{pH}$, toplam asitlik, renk, C vitamini, toplam fenolik madde, toplam flavonoid, antioksidan kapasite, HPLC ile şeker kompozisyonu ve GC-MS ile aroma kompozisyonu analizleri gerçekleştirilmiştir. Sonuçlar incelendiğinde Rubygem çeşidinin en yüksek kuru madde içeriğine sahip olduğu; Sabrina çeşidinin ise daha asidik karakteristiğe sahip olduğu bulgulanmıştır. Sabrina çeşidinin koyuluk, kırmızı renk ve sarı renk yoğunluklarının diğer iki çeşide kıyasla daha yüksek olduğu da belirlenmiştir. Biyoaktif madde içerikleri ve antioksidan kapasite yönünden Rubygem çeşidinin ön plana çıktığı anlaşılmaktadır. Rubygem çeşidi çileğin daha düşük miktarda sakaroz içerdiği; toplam şekerin büyük oranda indirgen şekerlerden (glikoz ve fruktoz) oluştuğu saptanmıştır. GC-MS ile aroma kompozisyonu analiz sonuçlarına göre Florida Fortuna, Sabrina ve Rubygem çeşitlerinde sırasıyla 16, 18 ve 20 adet uçucu bileşen tanımlanmış ve genel olarak meyve kokusu veren esterlerin tüm çileklerde etken bileşen olduğu gözlemlenmiştir.

Anahtar Kelimeler: Fragaria $x$ ananassa, Çilek, C vitamini, Fenolik madde, Antioksidan kapasite, Aroma bileşenleri

\section{ABSTRACT}

Aydın Province ranks second after Mersin in strawberry cultivation and exportation in Turkey. Within the scope of this study; physical, chemical, bioactive and aroma characteristics of commercial strawberry cultivars, which are mostly cultivated and exported within the borders of Aydın, were determined. In this context, total dry matter, $\mathrm{pH}$, total acidity, colour, vitamin C, total phenolic compounds, total flavonoid, antioxidant capacity, sugar composition by HPLC and aroma composition by GC-MS analyses were performed to commercially ripe strawberry cultivars which are Florida fortuna, Rubygem and Sabrina. The results showed that Rubygem cultivar had the highest dry matter content while Sabrina cultivar was found to have more acidic characteristics. It was also determined that the darkness, red colour and yellow colour indexes of Sabrina were higher than the other two cultivars. In terms of bioactive compounds and antioxidant capacity, Rubygem was observed as the foremost cultivar. Rubygem cultivar contains less sucrose than other strawberry cultivars; total sugar of this cultivar was found to consist largely of reducing sugars (glucose and fructose). According to the results of aroma composition analysis by GC-MS; 16, 18 and 20 volatile compounds were identified in Florida Fortuna, Sabrina and Rubygem cultivars and esters that give fruit odour were found to be active aroma components in all strawberry cultivars.

Key Words: Fragaria $x$ ananassa, Strawberry, Vitamin C, Phenolic compound, Antioxidant capacity, Aroma compounds 


\section{Giriş}

Çilek (Fragaria $x$ ananassa), ülkemizde yetiştiriciliği en çok tercih edilen meyvelerden biri olup ılıman bir iklim meyvesidir (Karahan ve ark., 2015). Üzümsü meyveler grubunda yer alan çilek, ülkemizde farklı çevre koşullarına sahip pek çok bölgede yetiştirilebilmektedir (Özgüven ve Yılmaz, 2009; Elik ve ark., 2017). Ülkemizde çilek üretimi her geçen yıl artan bir eğilim göstermektedir. 2012, 2013, 2014, 2015 ve 2016 yıllarında çilek üretimi sırasıyla 352, 372, 376, 376 ve 415 bin ton olarak gerçekleşmiştir (TÜik, 2016; Anonim, 2017).

Çilek meyvesi antioksidan, antienflamatuvar, antihiperlipidemik ve kan basıncını düşürücü etkilerinden dolayı fonksiyonel bir gıda olarak nitelendirilmektedir (Basu ve ark., 2014). Çilek meyvesinin antioksidan özelliğinin büyük ölçüde yapısında yer alan polifenoller ve vitaminlerden kaynaklandığı belirtilmektedir. Çileğin yapısında kuersetin, kaempferol, siyanidin, elajik asit, ve pelargonidin glikozitleri gibi yaklaşık 40 farklı fenolik bileşiğin varlığı literatürde bildirilmiştir (Aaby ve ark., 2007). Antioksidan kapasite üzerinde en etkili bileşenlerin ise askorbik asit, antosiyaninler ve ellagitanninler olduğu belirtilmektedir (Aaby ve ark., 2007). Proteggente ve ark. (2002) tarafından gerçekleştirilen çalışmada, Birleşik Krallıkta bulunan bazı meyve ve sebzelerin antioksidan kapasiteleri karşılaştırılmış ve en yüksek antioksidan kapasitenin çilek meyvesinde saptandığı bildirilmiştir. Bununla birlikte çilek, besinsel polifenoller açısından en zengin 100 gıda arasında yer almaktadır (Pérez-Jimenez ve ark., 2010).

Çilek meyvesinin bileşimi farklı çeşitler arasında farklılık göstermektedir. Özellikle fenolik kompozisyonlarının Amerika ve Avrupa'da yetiştirilen çilek çeşitleri arasında farklılıklar gösterdiği farklı çalışmalarda ortaya konulmuştur (Meyers ve ark., 2003; Stralsjö ve ark., 2003; Anttonen ve ark., 2006; Buendía ve ark., 2010). Yetiştirme sırasında uygulanan farklı zirai işlemlerin de çileklerin bazı özelliklerini etkilediği bilinmektedir (Wang ve Millner, 2009). Mejers ve ark. (2003) tarafından yapılan çalışmada Annapolis, Evangeline, Earliglow, Jewel, Sable, Mesabi, Sparkle ve Allstar çilek çeşitlerinin serbest fenolik bileşikler, flavonoidler, antosiyaninler ve toplam antioksidan kapasite yönünden; Wojdylo ve ark. (2009) tarafından yapılan çalışmada Kent ve Elsanta çilek çeşitlerinin toplam fenolik madde miktarı, toplam antosiyanin ve antioksidan aktivite yönünden; Wang ve Millner (2009) tarafından yapılan çalışmada Allstar ve Chandler çeşitlerinin toplam fenolik madde, toplam antosiyanin ve toplam flavonoller yönünden; Buendia ve ark. (2010) tarafından yapılan çalışmada ise Aguedilla, Albion, Camarosa, Candonga, Carmela, Chiflon, Cisco, Coral, Festival, Galexia, Macarena, Marina, Medina, Rubygem ve Ventana çeşitlerinin toplam fenolik madde ve toplam antosiyaninler yönünden farklılıklar gösterdiği tespit edilmiştir.

Bununla birlikte Özdemir ve ark. (2003) Hatay'da yetiştirilen dokuz çilek çeşidinde (Dorrit, Selva, Camarosa, Sweet Charlie, Seascape, Pajaro, Chandler, Tudla, Muir), Özgüven ve Yılmaz (2003) Adana'da yetiştirilen 9 farklı çilek çeşidinde (Oso Grande, Fern, Irvine, Laguna, Sweet Charlie, Selva, Seascape, Camarosa, Chandler), Kaynaş ve Günay (2003) Çanakkale'de yetiştirilen 11 farklı çilek çeşidinde (Sweet Charlie, Dorrit, Chandler, Evita, Delmarvel, Camarosa, Annapolis, Elsanta, Tudla ve Selva), Günay (2004) ise Çanakkale'de açıkta yetiştirilen yedi çilek çeşidi (Annapolis, Camarosa, Evita, Tudla, Elsanta, Elvira ve Delmarvel) ile plastik serada yetiştirilen 11 çilek çeşidinde (Annapolis, Camarosa, Evita, Tudla, Elsanta, Delmarvel, Sweet Charlie), kalite özellikleri yönünden çeşitli farklılıklar bulunduğunu tespit etmişlerdir. Ancak günümüze kadar yapılan çalışmalar içerisinde Aydın ilinde yetiştirilen Rubygem, Sabrina ve Florida Fortuna çeşitlerinin özelliklerinin incelendiği herhangi bir çalışmaya literatürde rastlanılmamıştır. Bu nedenle bu çalışmanın amacı Aydın ilinde yetiştirilen Rubygem, Sabrina ve Florida Fortuna çilek çeşitlerinin fiziksel, kimyasal, biyoaktif ve aroma özelliklerinin tespit edilmesidir. 


\section{Materyal ve Yöntem}

\section{Materyal ve kimyasallar}

Çalışmada Aydın ili Sultanhisar ilçesinde yetişen Florida Fortuna, Rubygem ve Sabrina çilek çeşitleri ticari hasat olgunluğunda temin edilmiş ve hızla Aydın Adnan Menderes Üniversitesi Gıda Mühendisliği Bölümü laboratuvarlarına taşınmıştır. Analizlerde kullanılan kimyasal ve standartlar analitik saflıkta olup Sigma-Aldrich (Missouri, ABD)'ten temin edilmiştir: Aseton, etanol, Folin-Ciocalteu ayracı, sodyum karbonat, 2,2-difenil-1-pikrilhidrazil (DPPH), gallik asit, kateşin, troloks, askorbik asit, okzalik asit, 2,6dikloroindofenol sodyum tuzu, C7-C30 alkan standart çözeltisi, fenolftalein, sodyum hidroksit, sakaroz, D-(+)-glikoz, D-(-)-fruktoz.

\section{Toplam kuru madde, asitlik, $p H$ ve renk analizleri}

Çilek örnekleri homojenizatörde (Ultraturrax IKA, T18) püre haline getirildikten sonra, darasI alınmış kurutma kaplarına 4-5 g örnek konularak $105{ }^{\circ} \mathrm{C}$ sıcaklıktaki etüvde 24 saat bırakılmıştır. Sabit tartıma gelen kurutulmuş örneklerin tartımları hassas terazide alınmıştır. Tartımdan önce örnekler, dış ortamdan nem kapmadan soğumaları amacıyla desikatöre konularak bekletilmiştir. Sonuçların ortalaması "\% toplam kuru madde" olarak ifade edilmiştir.

Çileklerin pH değeri, meyvenin ezilmesi ile elde edilen meyve suyunda $\mathrm{pH}$ metre ile ölçülmüştür. Asitlik tayini için $10 \mathrm{~g}$ çilek $100 \mathrm{ml}$ saf su ile homojenize edilmiş ve $20 \mathrm{ml}$ homojen çözelti $\mathrm{pH}$ 8.1 değerine ulaşana kadar $0.1 \mathrm{~N}$ sodyum hidroksit $(\mathrm{NaOH})$ ile titre edilmiştir. Titrasyonda harcanan $\mathrm{NaOH}$ miktarı esas alınarak toplam asitlik sitrik asit cinsinden '\%' olarak ifade edilmiştir.

Çileklerde renk özellikleri Hunter kolorimetre cihazı kullanılarak ölçülmüştür. Meyve rengi, CIE Lab renk değerleri olarak $L^{*}$ (aydınlık), a*(kırmııılık/yeşillik), b*(sarılık/mavilik) değerleri belirlenmiştir. CIE Lab renk değerlerinde L* ekseni aydınlık derecesini temsil ederken, a* değeri gıdanın kırmızılığı (+a) veya yeşilliğini (-a) ve b* değeri gıdanın sarılığını (+b) ve maviliğini (-b) ifade etmektedir.

\section{C vitamini analizi}

Çilek örneklerinin C vitamini miktarları Shrestha ve ark. (2016) tarafından belirtilen metoda göre spektrofotometrik (Shimadzu IU1800, Japonya) olarak belirlenmiştir. Bu amaçla çilek örnekleri püre haline getirildikten sonra \%0.4'lük okzalik asit çözeltisinden hazırlanan stabilizan çözelti ile karıştırılmıştır. Ardından deney tüplerine $1 \mathrm{ml}$ ekstraksiyon çözeltisi ve $9 \mathrm{ml}$ 2,6-diklorofenolindofenol çözeltisi eklenmiştir. Aynı işlem farklı tüplere, örnek çözeltisi yerine sadece stabilizan çözelti konularak yapılmıştır. Okzalik asit çözeltisi içeren örneklere karşı 2,6diklorofenolindofenol çözeltisi içeren örneklerin absorbansları $518 \mathrm{~nm}$ dalga boyunda ölçülmüştür. Örneklerin C vitamini miktarları mg $100 \mathrm{~g}^{-1}$ olarak ifade edilmiştir.

Toplam fenolik madde, toplam flavonoid ve antioksidan kapasite analizleri

Toplam fenolik madde, toplam flavonoid ve antioksidan kapasite analizlerinde kullanılan ekstraktların hazırlanmasında sap kısmından arındırılan çilek örnekleri ultraturaks ile parçalanarak \%70'lik aseton çözeltisi ile 1:5 (w/v) oranında karıştırılmıştır. Ardından karışım, çalkalamalı su banyosunda $55{ }^{\circ} \mathrm{C}$ sıcaklıkta, 50 rpm'de 1 saat süre ile bekletilmiş ve kaba filtre kağıdından geçirilerek ekstraktlar elde edilmiştir.

Toplam fenolik madde analizi, Sarkis ve ark. (2014)'nın önerdiği yönteme göre, bazı modifikasyonlar ile spektrofotometrik olarak gerçekleştirilmiştir. illk olarak $30 \mu \mathrm{L}$ ekstrakt, 2.37 $\mathrm{ml}$ deiyonize su ve $150 \mu \mathrm{L}$ Folin-Ciocalteu reaktifi ile oda sıcaklığında karıştııılmış ve karanlıkta $8 \mathrm{dk}$. bekletilmiştir. Ardından $450 \mu \mathrm{L}$ doygun sodyum karbonat çözeltisi eklenmiş ve vortekslenerek karıştırılmıştır. Etüvde $40{ }^{\circ} \mathrm{C}$ sıcaklıkta $30 \mathrm{dk}$. bekletilen karışımın $750 \mathrm{~nm}$ dalga boyundaki absorbans değeri UV-VIS spektrofotometre (Shimadzu V-1800, Japonya) ile ölçülmüştür. Sonuçlar, elde edilen kalibrasyon eğrisi ve örneklerin absorbans değerleri kullanılarak "mg gallik asit eşdeğeri (GAE) $100 \mathrm{~g}^{-1}$ örnek" cinsinden ifade edilmiştir.

Toplam flavonoid analizi, Kim ve ark. (2003)'nın 
yöntemine göre yapılmıştır. İlk olarak $1 \mathrm{ml}$ ekstrakt, $0.3 \mathrm{ml} \% 5^{\prime}$ lik $\mathrm{NaNO}_{2}$ ile karıştırılmış ve 5 dk. karanlıkta bekletilmiştir. Sonrasında $0.3 \mathrm{ml}$ $\% 10^{\prime}$ luk $\mathrm{AlCl}_{3} \cdot 6 \mathrm{H}_{2} \mathrm{O}$ ilave edilmiş ve $1 \mathrm{dk}$. beklendikten sonra $2 \mathrm{ml} 1 \mathrm{M} \mathrm{NaOH}$ eklenmiştir. Hemen ardından $2.4 \mathrm{ml}$ distile su eklenerek karışım vortekslenmiş ve $510 \mathrm{~nm}$ dalga boyunda absorbans okunmuştur. Sonuçlar "mg kateşin eşdeğeri (KE) $100 \mathrm{~g}^{-1}$ örnek" olarak ifade edilmiştir.

DPPH yöntemi ile antioksidan kapasite tayini ise, Grajeda-Iglesias ve ark. (2016)'na göre, bazı modifikasyonlar ile yapılmıştır. Öncelikle $0.1 \mathrm{ml}$ ekstrakt üzerine $2.9 \mathrm{ml} 0.1 \mathrm{mM}$ etanolde hazırlanmış DPPH çözeltisi eklenip çalkalanmış ve oda sıcaklığında, karanlıkta $30 \mathrm{dk}$. bekletilmiştir. Ardından absorbans değeri, $517 \mathrm{~nm}$ dalga boyunda UV-VIS spektrofotometrede ölçülmüştür. Antioksidan kapasite değerleri, " $\mu$ mol Troloks eşdeğeri (TE) $100 \mathrm{~g}^{-1}$ örnek" cinsinden ifade edilmiştir.

\section{HPLC ile şeker kompozisyonu}

Şeker bileşiminin belirlenmesinde $10 \mathrm{~g}$ çilek örnekleri bir behere alınmış ve üzerine $30 \mathrm{ml} \% 25$ EtOH çözeltisi ilave edilerek ultraturraks ile 6000 rpm'de 2 dakika parçalanmıştır. Karışım daha sonra $50 \mathrm{ml}$ lik balon jojeye aktarılmış ve \%25 EtOH çözeltisi ile hacim çizgisine tamamlandıktan sonra $0.45 \mu m^{\prime}$ lik filtreden (Sartorius RC, Goettingen, Almanya) geçirilmiş ve HPLC'ye enjekte edilmek üzere viallere aktarılmıştır. Örnekler ve hazırlanan standartlar HPLC'ye (Shimadzu Prominence LC-20A) enjekte edilmiştir. Aminex HPX-87P karbonhidrat kolonu (300 x 7.8 $\mathrm{mm} ; 80^{\circ} \mathrm{C}$ ) ve Refraktif indeks dedektör (RID)'ün kullanıldığı çalışmada LC su mobil fazının akış hızı $0.6 \mathrm{ml}^{-\mathrm{dk}^{-1}}$ olarak belirlenmiştir (Rupérez ve Toledano, 2003).

\section{GC-MS ile aroma bileşenleri analizi}

Çilek çeşitlerindeki uçucu bileşenler statik tepe boşluğu katı faz mikro ekstraksiyon (solid phase micro extraction-SPME) yöntemiyle gaz kromatografisi kütle spektrometresinde (GC-MS) tayin edilmiştir. Bu amaçla, 10'ar gram örnek püre haline getirilerek $20 \mathrm{ml}$ 'lik SPME viallerine konularak tepe boşluğu ünitesine yerleştirilmiştir (Agilent 7820A/5975C GC-MS, Agilent Technologies Inc., Santa Clara, CA, ABD). Örnekler 15 dakikalık dengelenme süresince bekletilmiş ve örneklerin tepe boşluğu SPME fiberine $65{ }^{\circ} \mathrm{C}$ sıcaklıkta 60 dakika maruz bırakılmıştır. Daha sonra transfer kolonuyla örnekler $0.5 \mathrm{ml} / \mathrm{s}$ hızla gaz kromatografisine enjekte edilmiştir. Enjeksiyon inlet sıcaklığı $200{ }^{\circ} \mathrm{C}$ olup analiz için HP-5 kolonu kullanılmıştır $(30 \mathrm{~m} \times 0.32 \mathrm{~mm}$ i.d. $\times$ $0.25 \mu \mathrm{m})$. Taşıyıcı gaz olarak helyum $1 \mathrm{ml} / \mathrm{s}$ hızla kullanılmıştır. GC-MS parametreleri; fırın sıcaklığı $50{ }^{\circ} \mathrm{C}^{\prime}$ de $1 \mathrm{dk}$., daha sonra $4{ }^{\circ} \mathrm{C} \cdot \mathrm{dk}^{-1}$ artışla 200 ${ }^{\circ} \mathrm{C}^{\prime}$ de $15 \mathrm{dk}$. ve final sıcaklığı ise $20^{\circ} \mathrm{C} \cdot \mathrm{dk}^{-1}$ artışla $230{ }^{\circ} \mathrm{C}^{\prime}$ de 15 dakika olarak programlanmıştır. Split oranı 1:50 olarak ayarlanmış ve kütle spektrumu 70e/V'de toplam iyon kromatogram (TIC) modunda taranmıştır Uçucu bileşenlerin tutunma endeksleri, C7-C30 alkan standart çözeltisinin yukarıda belirtilen şartlarda cihaza enjekte edilmesiyle hesaplanmıştır. Uçucu bileşenlerin tanımlanması, bileşenlerin kütle spektralarının Wiley spektral kütüphanesi verileriyle ve tutunma endeksleri National Institute of Standards and Technology (NIST) kütüphanesi verileri ile karşılaştırılarak yapılmıştır.

\section{istatistiksel analiz}

Verilerin istatistiksel değerlendirilmesi SPSS paket programı (SPSS Inc., Chicago, IL, ABD) ile yapılmıştır. Elde edilen verilerde $(n=3)$, sonuçlar üzerine parametrelerin etkisi varyans analizi ile tespit edilmiş ve ortalamalar arasındaki farklılık $(P<0.05)$ Duncan çoklu karşılaştırma testi ile belirlenmiştir.

\section{Araştırma Bulguları ve Tartışma}

Üç farklı çilek çeşidinde belirlenen toplam kuru madde (\%), asitlik (\%), $\mathrm{pH}$ ve renk değerleri Çizelge 1'de sunulmuştur. Sonuçlar incelendiğinde Rubygem çeşidi çileğin en yüksek ortalama kuru madde içeriğine sahip olduğu; bu çeşidi Sabrina çeşidinin takip ettiği görülmektedir. Asitlik ve $\mathrm{pH}$ değerlerinin birbiriyle uyumlu oldukları ve Sabrina 
çilek çeşidinin daha asidik karakteristiğe sahip olduğu anlaşılmaktadır. Renk değerleri incelendiğinde, Sabrina çeşidi çileklerde koyuluk, kırmızı renk ve sarı renk yoğunluklarının diğer iki çeşide kıyasla daha yüksek olduğu görülmektedir. Toplam asitlik açısından Sabrina çilek çeşidi Florida Fortuna ve Rubygem çilek çeşitlerden anlamlı $(P<0.05)$ fark göstermiştir. Buna karşı, üç farklı çilek çeşidinin $\mathrm{pH}$ değerleri arasında önemli düzeyde fark bulunmamıştır. Akçay (2014) tarafından farklı azot dozları uygulanarak yetiştirilen Rubygem ve Florida Fortuna çilek çeşitlerinde ortalama titre edilebilir asitlik değerleri sırasıyla $\% 0.25$ ve $\% 0.29$ olarak belirlenmiştir. Bu çalışmada elde edilen asitlik değerlerinin daha yüksek olduğu görülmektedir. $\mathrm{Bu}$ durum farklı çevresel koşullardan kaynaklanabileceği gibi, meyve olgunluğu ile de ilişkilidir. Atasay ve Türemiş (2008) tarafından organik yetiştiricilik uygulamalarının çileklerin kalite özelliklerine etkisi ile ilgili yapılan bir çalışmada farklı yıllara ait Camarosa çeşidi çilek örneklerinde en yüksek $\mathrm{pH}$ değerleri 3.71 ve 3.84 olarak belirlenmiştir. Çalışmada elde edilen $\mathrm{pH}$ değerleri, literatürde çilekler için belirlenen $\mathrm{pH}$ değerleri ile uyumlu bulunmuştur.

Çizelge 1. Çilek çeşitlerine ait toplam kuru madde, asitlik, $\mathrm{pH}$ ve renk değerleri

Table 1. Total dry matter, acidity and $\mathrm{pH}$ values of strawberry cultivars

\begin{tabular}{ccccccc}
\hline Çilek çeşidi & $\begin{array}{c}\text { Toplam kuru } \\
\text { madde (\%) }\end{array}$ & Asitlik (\%) & $\mathrm{pH}$ değeri & $\mathrm{L}^{*}$ & $\mathrm{a}^{*}$ & $\mathrm{~b}^{*}$ \\
\hline $\begin{array}{c}\text { Strawberry } \\
\text { cultivar }\end{array}$ & $\begin{array}{c}\text { Total dry matter } \\
(\%)\end{array}$ & Acidity (\%) & $\mathrm{pH}$ value & $\mathrm{L}^{*}$ & $\mathrm{a}^{*}$ & $\mathrm{~b}^{*}$ \\
\hline Florida Fortuna & $7.46 \pm 0.03^{\mathrm{a}}$ & $0.63 \pm 0.06^{\mathrm{a}}$ & $4.43 \pm 0.12^{\mathrm{a}}$ & $14.60 \pm 3.28^{\mathrm{a}}$ & $27.41 \pm 3.03^{\mathrm{a}}$ & $15.86 \pm 3.29^{\mathrm{a}}$ \\
\hline Rubygem & $9.63 \pm 0.14^{\mathrm{b}}$ & $0.57 \pm 0.05^{\mathrm{a}}$ & $4.40 \pm 0.02^{\mathrm{a}}$ & $15.38 \pm 2.28^{\mathrm{a}}$ & $30.17 \pm 1.81^{\mathrm{b}}$ & $17.28 \pm 2.41^{\mathrm{a}}$ \\
\hline Sabrina & $9.20 \pm 0.17^{\mathrm{c}}$ & $0.67 \pm 0.03^{\mathrm{b}}$ & $4.35 \pm 0.03^{\mathrm{a}}$ & $18.96 \pm 2.81^{\mathrm{b}}$ & $33.30 \pm 1.74^{\mathrm{c}}$ & $19.19 \pm 2.61^{\mathrm{b}}$ \\
\hline
\end{tabular}

Aynı sütunda yer alan farklı harfler istatistiki farklılıkları simgelemektedir $(P<0.05)$

Ornelas-Paz ve ark. (2013) yaptıkları çalışmada altı farklı olgunlaşma periyodunda hasat edilen organik çileklerin fiziksel ve kimyasal özelliklerini belirleyerek değişimlerini incelemişlerdir. Olgunlaşmamış çileklerin ilk periyodunda titre edilebilir asitlik değerleri \%1.2 iken bu değer olgunlaşma süresince giderek azalarak olgunluğa erişmiş hasat edilen çileklerde \%0.7 olarak belirlenmiştir. Çalışmamızda üç farklı çilek çeşidinde belirlenen titre edilebilir asitlik değerleri (\%0.57- \%0.67), Ornelas-Paz ve ark. (2013) tarafından olgunluğa erişmiş çileklerde belirlenen titre edilebilir asitlik değerlerine oldukça yakın olduğu görülmüştür.

Renk, çileklerin olgunlaşma zamanının belirlenmesinde kullanılan önemli bir kalite kriteri olup, arzu edilen meyve renginin oluşumunda antosiyaninler etkili olmaktadır (Gündüz ve Özdemir, 2012). Özellikle çilek, ahududu, böğürtlen ve karadut gibi kırmızı renkli meyvelerde olgunlaşma süresince antosiyaninlerin oluşumu sonucu meyvede a* renk değerinin artışı görülmektedir. Meyve olgunluğunun belirlenmesinde, meyve renginin görsel olarak değerlendirilmesi uyumlu sonuçlar vermektedir (Stavang ve ark., 2015). Bununla birlikte, çileklerde meyve rengi tüketici tercihinde önemli rol oynayan ve meyvenin pazar değerini artıran en temel faktördür. Renk değerlerinden $a^{*}$ (kırmızılık) değerinin artması, çilek meyvesinde meyve olgunluğunun ve pigment birikiminin bir göstergesi olarak bilinmektedir (Karakaya ve ark., 2015). Renk değerleri incelendiğinde, Sabrina çeşidi çileklerde koyuluk, kırmızı renk ve sarı renk yoğunluklarının diğer iki çeşide kıyasla daha yüksek olduğu görülmektedir. En düşük kırmızı renk yoğunluğu Florida Fortuna çeşidi çileklerde elde edilmiştir. Florida Fortuna, Rubygem ve Sabrina çilek çeşitlerinin kırmızılık değerleri arasında anlamlı fark bulunmuştur. Gerek meyvelerin çeşidi ve gerekse bulunduğu ekolojik koşullara göre renk değerleri farklılık gösterebilmektedir.

\section{Biyoaktif özellikler}

Çilek çeşitlerinin biyoaktif madde içerikleri olan C vitamini, toplam fenolik madde, toplam flavonoid ve antioksidan kapasite değerlerinin 
hepsinde en yüksek değerlere sahip olarak Rubygem çilek çeşidi ön plana çıkmaktadır. Sonuçların dünya genelindeki çilek çeşitleriyle ortalama olarak uyumlu olduğu; üstelik Sultanhisar'da yetiştirilen bu üç çeşidin literatür taraması yapılan çoğu çilek çeşitlerinden biyoaktif maddelerce daha zengin oldukları anlaşılmaktadır.
Aydın ilinde yetiştirilen farklı çilek çeşitlerinin C vitamini miktarları Çizelge 2'de verildiği gibidir. En yüksek C vitamini içeren çilek çeşidinin Rubygem (54.61 mg/100g) olduğu tespit edilmiş olup bunu sırasıyla Florida Fortuna (53.40 mg $100 \mathrm{~g}^{-1}$ ) ve Sabrina (50.46 mg $100 \mathrm{~g}^{-1}$ ) çeşitleri takip etmiştir.

Çizelge 2. Çilek çeşitlerine ait biyoaktif madde miktarları (GAE: Gallik asit eşdeğer; KE: Kateşin eşdeğer; TE: Troloks eşdeğer)

Table 2. Bioactive compounds of strawberry cultivars (GAE: Gallic acid equivalent; CE: Catechin equivalent; TE: Trolox equivalent)

\begin{tabular}{|c|c|c|c|c|}
\hline Çilek çeşidi & $\begin{array}{l}\text { C vitamini } \\
\left(\mathrm{mg} 100 \mathrm{~g}^{-1}\right)\end{array}$ & $\begin{array}{l}\text { Toplam fenolik madde } \\
\left(\mathrm{mg} \mathrm{GAE} 100 \mathrm{~g}^{-1}\right)\end{array}$ & 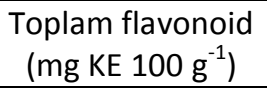 & $\begin{array}{c}\text { Antioksidan kapasite } \\
\left(\mu \mathrm{mol} \text { TE } 100 \mathrm{~g}^{-1}\right)\end{array}$ \\
\hline $\begin{array}{l}\text { Strawberry } \\
\text { cultivar }\end{array}$ & 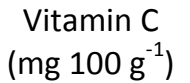 & $\begin{array}{l}\text { Total phenolic compound } \\
\left(\mathrm{mg} \mathrm{GAE} 100 \mathrm{~g}^{-1}\right)\end{array}$ & $\begin{array}{l}\text { Total flavonoid } \\
\left(\mathrm{mg} \mathrm{CE} 100 \mathrm{~g}^{-1}\right)\end{array}$ & $\begin{array}{l}\text { Antioxidant capacity } \\
\left(\mu \mathrm{mol} \text { TE } 100 \mathrm{~g}^{-1}\right)\end{array}$ \\
\hline Florida Fortuna & $53.40 \pm 1.7^{a}$ & $239.6 \pm 10.5^{\mathrm{a}}$ & $62.2 \pm 2.7^{\mathrm{a}}$ & $329.6 \pm 0.2^{\mathrm{a}}$ \\
\hline Rubygem & $54.61 \pm 1.2^{\mathrm{a}}$ & $245.1 \pm 20.1^{\mathrm{a}}$ & $67.8 \pm 4.3^{b}$ & $331.0 \pm 0.4^{\mathrm{a}}$ \\
\hline Sabrina & $50.46 \pm 1.9^{b}$ & $169.6 \pm 15.5^{b}$ & $57.4 \pm 2.4^{\mathrm{a}}$ & $329.2 \pm 2.1^{\mathrm{a}}$ \\
\hline
\end{tabular}

Aynı sütunda yer alan farklı harfler istatistiki farklılıkları simgelemektedir $(P<0.05)$

Çalışmada, Aydın ilinde yetiştirilen çilek çeşitlerinin C vitamini miktarlarının ülkemizde farklı bölgelerde yetiştirilen çilek çeşitlerine benzer olduğu görülmüştür. Özbahçali (2014) tarafından yapılan çalışmada Erzurum şartlarında yetiştirilen bazı çilek çeşitlerinin (Sweet Ann, Crystal, Fern, Redlands Hope, Kabarla ve Rubygem) C vitamini miktarları incelenmiş ve miktarlarının 38.0-55.3 mg $100 \mathrm{ml}^{-1}$ arasında değiştiği görülmüştür. En düşük $C$ vitamini miktarının Redlands Hope çeşidinde, en yüksek miktarın ise Rubygem çeşidinde saptandığı belirtilmiştir. Yıldız ve ark. (2014) tarafından gerçekleştirilen çalışmada ise ülkemizin kuzeydoğu bölgesinde yetiştirilen 15 farklı çeşit dağ çileğinin $C$ vitamini miktarları analiz edilmiş ve miktarların $38.55 \mathrm{mg} 100 \mathrm{~g}^{-1}$ ile $57.37 \mathrm{mg} 100 \mathrm{~g}^{-1}$ aralığında değiştiği bildirilmiştir. Koyuncu ve Dilmaçünal (2010) tarafından yapılan çalışmada Isparta ilinde yetiştirilen Dorit ve Selva isimli çilek çeşitlerinin ortalama $\mathrm{C}$ vitamini miktarlarının sırasıyla $24.70 \mathrm{mg} 100 \mathrm{~g}^{-1}$ ve $15.25 \mathrm{mg} 100 \mathrm{~g}^{-1}$ olduğu rapor edilmiş, Pırlak ve Köse (2009) tarafından yapılan çalışmada, Erzurum ilinde yetiştirilen Selva çeşidine ait çileğin C vitamini miktarının $52.7 \mathrm{mg} 100 \mathrm{~g}^{-1}$ olarak belirlendiği belirtilmiştir. Akbulut ve ark. (2006) tarafından yapılan çalışmada ise Tokat yöresinden 4 farklı çilek çeşidi (Gökal 1, Gökal 2, Maraline ve
Fragaria vesca) ile Konya-Akşehir yöresinden Fragaria arten çeşidi çileklerin askorbik asit miktarları incelenmiş ve en yüksek miktarda askorbik asit içeren çilek çeşidinin $75.5 \mathrm{mg} 100 \mathrm{~g}^{-1}$ ile Fragaria vesca (dağ çileği) olduğu saptanmıştır.

Aydın ilinde yetiştirilen çileklerin C vitamini miktarlarının yurtdışında bazı bölgelerde yetiştirilen çileklerin $C$ vitamini miktarları ile de yakın olduğu belirlenmiştir. Konu ile ilgili NuñezMancilla ve ark. (2013) tarafından yapılan çalışmada Şili'de analiz edilen çileğin (Fragaria vesca cv. Camarosa) C vitamini miktarının 47.09 mg $100 \mathrm{~g}^{-1}$ olduğu, Pineli ve ark. (2011) tarafından yapılan çalışmada Brezilya'da yetiştirilen Osogrande ve Camino Real çeşidine ait çileklerin C vitamini miktarlarının sırasıyla 31.4-46.5 mg 100g1 olduğu, Hakala ve ark. (2003) tarafından yapılan çalışmada ise Finlandiya'da yetiştirilen 6 farklı çilek çeşidinin (Jonsok, Korono, Polka, Honeoye, Bouty ve Senga Sengana) C vitamini miktarlarının 32.40-84.70 mg $100 \mathrm{~g}^{-1}$ arasında değiştiği tespit edilmiştir.

Çilek meyvesinde yer alan temel polifenol sınıfları antosiyaninler, ellagitaninler ve proantosiyanidinlerdir (Sandhu ve ark., 2018). Çilek meyve etinin kırmızı renginden sorumlu olarak ise, antosiyaninlerden pelargonidin ve siyanidin glikozitlerinin baskın bileşenler oldukları bildirilmektedir (Aaby ve ark., 2005). Çilekte yer 
alan antosiyanin miktarının, toplam polifenollerin \%75'inden fazlasını oluşturduğu ve $100 \mathrm{~g}$ çilekte 20 - 60 mg arasında değiştiği bildirilmiştir (Sandhu ve ark., 2018). Totem ve Puget Reliance cinsi çilekler ile yapılan bir çalışmada, toplam fenolik madde içeriği 230 - 340 mg GAE $100 \mathrm{~g}^{-1}$ aralığında bulgulanmıştır. Antioksidan kapasitesi değerleri ise ORAC yöntemine göre $13 \mu \mathrm{mol} \mathrm{TEg}^{-1}$; FRAP yöntemine göre ise $4.3 \mathrm{mmol} T E 100 \mathrm{~g}^{-1}$ olarak rapor edilmiştir (Aaby ve ark., 2005).

Wang ve Lin (2000), farklı çilek çeşitleri ile yaptıkları analizler sonucunda toplam fenolik madde miktarını 95 - 152 mg $100 \mathrm{~g}^{-1}$, ORAC (oksijen radikal absorbans kapasitesi) yöntemi ile elde ettikleri antioksidan kapasite değerlerini ise 12.2 - $17.4 \mu \mathrm{mol} \mathrm{TEg}^{-1}$ aralıklarında rapor etmişlerdir. Bir başka çalışmada, Kent ve Elsanta isimli iki farklı çilek çeşidi için toplam fenolik madde değerleri sırasıyla 1901.9 ve 2405.9 mg $100 \mathrm{~g}^{-1}$ kuru çilek, DPPH yöntemi ile elde edilen antioksidan kapasite değerleri ise sırasıyla 21.0 ve $24.3 \mu \mathrm{M}$ TE $100 \mathrm{~g}^{-1}$ kuru çilek olarak bildirilmiştir (Wojdylo ve ark., 2009). Mevcut çalışma kapsamında elde edilen toplam fenolik madde miktarı ve antioksidan kapasite değerleri literatür bulguları ile kıyaslandığında, Aydın ili Sultanhisar ilçesinde yetişen ticari çilek çeşitlerinin antioksidan bileşenlerce zengin oldukları ifade edilebilir. Öz ve Eker (2016), Osmaniye ilinde yetişen Rubygem ve Osmanlı isimli iki farklı ticari çilek türü ile yaptıkları çalışmalarında sırasıyla toplam fenolik madde miktarını 3774 ve $3053 \mathrm{mg}$ $\mathrm{kg}^{-1}$, toplam flavonoid miktarını 121.7 ve $36.5 \mathrm{mg}$ $\mathrm{kg}^{-1}$ ve antioksidan kapasite değerini ise DPPH süpürme aktivitesi cinsinden $\% 91.0$ ve $\% 58.6$ olarak rapor etmişlerdir. Benzer şekilde, bu çalışma kapsamında Aydın ilinde yetişen Rubygem çeşidinin, çalışılan diğer çilek çeşitlerine kıyasla fenolik maddelerce daha zengin olduğu bulgulanmıştır. Fenolik maddeler ile antioksidan kapasite ilişkisi ele alındığında ise, çilek meyvesi ile yapılan bir çalışmada toplam fenolik madde ve antosiyanin miktarının, antioksidan kapasite değeri ile pozitif yönde anlamlı bir ilişkisinin olduğu bildirilmiştir. Ayrıca, askorbat içeriğinin de antioksidan madde içeriği ile negatif yönde anlamlı bir ilişkisinin olduğu ifade edilmiştir (Kalt ve ark., 1999).

\section{Şeker kompozisyonu}

Sultanhisar'da yetiştirilen üç çilek çeşidinin HPLC ile detaylı şeker kompozisyonu ayrıca belirlenmiştir (Çizelge 3). Her üç çilek çeşidinde de baskın şekerin glikoz olduğu; glikozu sırasıyla früktozun ve sakarozun takip ettiği anlaşılmaktadır. En yüksek toplam şekerin Sabrina çeşidinde olduğu ve en düşük de Florida Fortuna çeşidinde olduğu bulgulanmıştır. Farklı olarak, Rubygem çeşidi çilek örneklerinde sakaroz miktarı diğer çeşitlere kıyasla oldukça düşük tespit edilmiştir.

Çizelge 3. Çilek çeşitlerine ait HPLC ile şeker analizi sonuçları

Table 3. Results of sugar analysis by HPLC belonging to strawberry cultivars

\begin{tabular}{|c|c|c|c|c|}
\hline Çilek çeşidi & 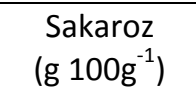 & $\begin{array}{c}\text { Glikoz } \\
\left(g^{\left.100 g^{-1}\right)}\right.\end{array}$ & 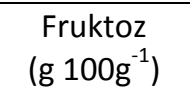 & 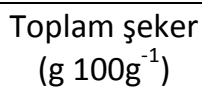 \\
\hline Strawberry cultivar & 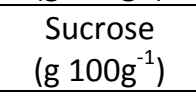 & 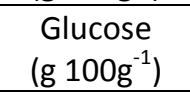 & 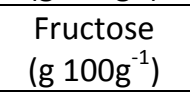 & 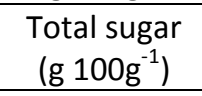 \\
\hline Florida Fortuna & $1.51 \pm 0.14^{\mathrm{a}}$ & $2.24 \pm 0.28^{a}$ & $2.06 \pm 0.26^{a}$ & $5.81 \pm 0.68^{\mathrm{a}}$ \\
\hline Rubygem & $0.36 \pm 0.19^{b}$ & $3.10 \pm 0.39^{b}$ & $2.77 \pm 0.32^{b}$ & $6.23 \pm 0.89^{\mathrm{a}}$ \\
\hline Sabrina & $1.88 \pm 0.14^{c}$ & $3.22 \pm 0.00^{b}$ & $2.93 \pm 0.02^{b}$ & $8.03 \pm 0.17^{b}$ \\
\hline
\end{tabular}

Aynı sütunda yer alan farklı harfler istatistiki farklılıkları simgelemektedir $(P<0.05)$

\section{Aroma Özellikleri}

Aydın ili Sultanhisar ilçesinde yetişmekte olan üç çilek çeşidi Sabrina, Florida Fortuna ve Rubygem türlerinde uçucu bileşen tayini statik tepe boşluğu yöntemiyle gaz kromatografisi kütle spetrometresinde yapılmıştır. Dünyada bazı çilek çeşitlerinin tepe boşluğu bileşenlerinde yapılan çalışmalardaki durum ise Çizelge 4'te özetlenmiştir. 
Çizelge 4. Çilek türlerinde yapılan çalışmalarda en fazla bulunan üç tepe boşluğu aroma bileşenleri

Table 4. Three headspace aroma compounds mostly determined in studies of strawberry cultivars

\begin{tabular}{lll}
\hline Çilek Çeşidi & En fazla bulunan bileşenler & Kaynak \\
\hline Strawberry cultivar & Major compounds & Reference \\
\hline Honeoye & Hekzil asetat, aseton, butil asetat & Nielsen ve Leufven, 2008 \\
Korona & Metil butanat, etil butirat, aseton & Nielsen ve Leufven, 2008 \\
Tamar & Etil butanat, etil hekzanat, E-2-hekzenal & Kafkas ve ark., 2005 \\
Yael & Etil butanat, butil butanat, E-2-hekzenal & Kafkas ve ark., 2005 \\
Malach & Etil hekzanat, E-2-hekzenal ve etil hekzanal & Kafkas ve ark., 2005 \\
Totem & Etil butanat, oktil butanat, benzil asetat & Jetti ve ark., 2007 \\
Puget Relieance & Hekzanoik asit, etil butanat, benzil asetat & Jetti ve ark., 2007 \\
Puget Summer & Hekzanoik asit,etil butanat, 2-metil butanoik asit & Jetti ve ark., 2007 \\
Hood & Hekzanoik asit,hekzil hekzanat, nerolidol & Jetti ve ark., 2007 \\
Independence & 2-Metil butanoik asit, hekzanoik asit,benzen metanol & Jetti ve ark., 2007 \\
Ventana & Hekzanoik asit, linalil format, etil sinamat & Jetti ve ark., 2007 \\
Camarosa & Hekzanoik asit, delta-dekalakton, oktil-2-metil butanat & Jetti ve ark., 2007 \\
San Mugiel & Hekzanoik asit, metil butanat, etil sinamat & Jetti ve ark., 2007 \\
Venice & Etil asetat, etil sinamat, mesifuran & Jetti ve ark., 2007 \\
$13 G 97$ & Hekzanoik asit, nerolidol, gama-dekalakton & Jetti ve ark., 2007 \\
\hline
\end{tabular}

Çizelge 5. Sabrina, Florida Fortuna ve Rubygem çilek çeşitlerinin uçucu bileşenleri ve koku özellikleri

Table 5. Volatile compounds and odour properties of Sabrina, Florida Fortuna and Rubygem strawberry cultivars

\begin{tabular}{|c|c|c|c|c|c|c|c|}
\hline \multirow[b]{3}{*}{ No } & \multirow[b]{3}{*}{$\begin{array}{c}\text { Retensiyon } \\
\text { Zamanı }\end{array}$} & \multirow[b]{3}{*}{$\begin{array}{c}\text { Retensiyon } \\
\text { Endeksi }^{1}\end{array}$} & \multirow[b]{3}{*}{ Bileşen } & \multirow[b]{3}{*}{ Koku özelliği ${ }^{2}$} & \multicolumn{3}{|c|}{ GC-MS Alan Yüzdeliği (\%) } \\
\hline & & & & & GC-M & rea Perce & ge (\%) \\
\hline & & & & & Sabrina & $\begin{array}{l}\text { Florida } \\
\text { Fortuna }\end{array}$ & Rubygem \\
\hline No & $\begin{array}{l}\text { Retention } \\
\text { time }\end{array}$ & $\begin{array}{c}\text { Retention } \\
\text { Index }\end{array}$ & Compound & Odour properties $^{2}$ & & & \\
\hline 1 & 1.601 & $<600$ & Asetone & Oje çıkarıcı & 25.87 & 42.93 & 21.01 \\
\hline 2 & 1.672 & $<600$ & Metil asetat & Etherimsi & 10.76 & 11.41 & 17.71 \\
\hline 3 & 1.844 & $<600$ & Diasetil & Tereyağı & 4.36 & 3.43 & $n d^{3}$ \\
\hline 4 & 1.957 & 609 & Etil asetat & Ananas & 23.11 & 8.55 & 19.59 \\
\hline 5 & 2.04 & 622 & Metil propanal & Meyvemsi & nd & 0.42 & 0.29 \\
\hline 6 & 2.23 & 654 & İzopripil asetat & Eterimsi & nd & 0.60 & 0.28 \\
\hline 7 & 2.42 & 685 & 2,2,4,4-Tetrametil butan & (kokusuz) & 14.40 & 9.49 & 6.18 \\
\hline 8 & 2.634 & 715 & Etil propanat & Meyvemsi & 0.11 & 0.52 & 0.29 \\
\hline 9 & 2.741 & 726 & Metil butanat & Eter ve meyvemsi & 6.29 & 8.17 & 11.64 \\
\hline 10 & 2.865 & 738 & 1-Pentanol & Meyvemsi & 0.51 & nd & 0.36 \\
\hline 11 & 2.937 & 744 & 3-metil-2-pentanon & (kokusuz) & 0.44 & nd & nd \\
\hline 12 & 3.311 & 773 & Toluen & Yağlı boya & 0.95 & nd & 0.16 \\
\hline 13 & 3.423 & 780 & Metil izovalerat & Meyvemsi & 0.57 & nd & 0.57 \\
\hline 14 & 3.797 & 802 & Etil butanat & Elma & 3.51 & 7.21 & 5.80 \\
\hline 15 & 4.581 & 847 & Propil butanat & Meyvemsi & nd & 0.59 & 0.31 \\
\hline 16 & 4.824 & 858 & E-2-Hekzenal & Yeşil yaprak & 0.50 & 0.54 & 0.15 \\
\hline 17 & 5.162 & 872 & 1-Hekzanol & Reçine, çiçek ve yeşil yaprak & 0.94 & nd & 1.32 \\
\hline 18 & 6.581 & 928 & Metil hekzanat & Meyve ve çiçek & 4.97 & 2.09 & 6.27 \\
\hline 19 & 8.836 & 1000 & Etil hakzanat & Elma kabuğu & 1.80 & 2.27 & 3.52 \\
\hline 20 & 9.293 & 1016 & Hekzil asetat & Meyvemsi ve bitkisel & nd & nd & 0.56 \\
\hline 21 & 9.387 & 1020 & E-2-Hekzenil asetat & Yeşil yaprak & 0.21 & 0.70 & 0.80 \\
\hline 22 & 12.184 & 1100 & delta-3- Karen & Limon ve reçine & 0.71 & 0.55 & 0.62 \\
\hline
\end{tabular}

${ }^{1}$ Retensiyon endeksleri gaz kromatografisi HP1 kolonunda C7-C30 alkan serisine göre hesaplanmıştır. ${ }^{2}$ Bileşenlerin koku özellikleri www.flavornet.org ve www.thegoodscentscompany.com veri tabanlarından derlenmiştir. ${ }^{3}$ nd: Bileşen bulunamamıştır.

Sultanhisar çileklerinin tepe boşluğu bileşenleri ve çeşitli kaynaklarda belirtilen aroma özellikleri Çizelge 5'te görülmektedir. Sabrina, Florida fortuna ve Rubygem çeşitlerinde sırasıyla 18, 16 ve 20 adet uçucu bileşen saptanmıştır. Bileşenlerin birçoğunun ester grubuna ait olduğu belirlenmiştir. Genel olarak en yüksek oranda bulunan bileşikler aseton (oje çıkarıcı kokusu), metil asetat (eterimsi koku), etil asetat (ananas kokusu), 2,2,4,4-tetrametil butan (kokusuz bileşen), metil butanat (eter ve meyvemsi koku), etil butanat (elma kokusu) ve metil hekzanattır 
(meyve ve çiçek kokusu). Sabrina çeşidinin en fazla bulunan üç aroma bileşeni aseton, etil asetat ve metil asetat; Florida fortuna çeşidinin en fazla bulunan üç aroma bileşeni aseton, metil asetat ve metil butanat; Rubygem çeşidinin ise en fazla bulunan üç aroma bileşeni aseton, etil asetat ve metil butanat olarak belirlenmiştir.

Çilek örneklerinin uçucu bileşen içerikleri, ilgili bileşenin kromatogramdaki relatif yüzdelikleri ile hesaplanmıştır. Üç çilek çeşidinde; 14 ester, 3 keton, 2 alkol, 2 aromatik hidrokarbon ve 1 alkan olmak üzere toplam 22 bileşen tespit edilmiştir. Bu sonuçlara benzer olarak; Hakala ve ark. (2002) 6 çilek türünde (Senga Sengena, Jonsok, Polka, Korona, Bounty ve Honeoye) en fazla miktarda bulunan uçucu bileşen grubunun ester grubu olduğunu ve metil butanat, etil butanat, metil hekzanat ve ethyl hekzanatın başlıca bileşenler olduğunu belirtmiştir. Bu çalışmada; Sabrina türünün en fazla bulunan üç aroma bileşeni aseton (\%25.87), etil asetat (\%23.11) ve metil asetat (\%10.76); Florida Fortuna çeşidinin en fazla bulunan üç aroma bileşeni aseton (\%42.93), metil asetat (\%11.41) ve etil asetat (\%8.55); Rubygem çeşidinin ise en fazla bulunan üç aroma bileşeni aseton (\%21.01), etil asetat (\%19.59) ve metil butanat (\%17.71) olarak belirlenmiştir. Florida fortuna ve Sabrina çeşitlerinin en fazla bulunan uçucu bileşenleri aynı olmasına rağmen, iki tür arasındaki aroma farklılaşması daha az miktarda bulunan bileşen miktar ve çeşitlerinden kaynaklanmaktadır. Benzer yöntem kullanılarak daha önce yapılmış çalışmalarda diğer çilek çeşitlerinin en fazla bulunan uçucu bileşenleri Çizelge 4'te özetlenmiştir. Buna göre; bu çalışmada tanımlanan Florida fortuna, Sabrina ve Rubygem çilek çeşitlerinin başlıca uçucu bileşenlerinin diğer çilek çeşitlerinden farklılık gösterdiği, ancak genel olarak meyve kokusu veren esterlerin tüm çileklerde etken bileşen olduğu gözlemlenmiştir.

\section{SONUÇLAR}

Dünyanın önemli çilek üreticisi ülkeleri arasında yer alan ülkemizin Ege Bölgesi'nde Aydın ilinin Sultanhisar ilçesinde büyük ölçüde yetiştiriciliği yapılan ve önemli bir pazar payı olan çilek çeşitleri Florida Fortuna, Rubygem ve Sabrina çeşitleridir. Bu çalışmada, Sultanhisar yöresinde yetiştiriciliği hız kazanan bu üç farklı çilek çeşidinin fiziksel, kimyasal, biyoaktif ve aroma özellikleri incelenmiştir. Çilek çeşitliliğine bağlı olarak meyve kalite özellikleri ve kimyasal kompozisyonlarındaki farklılıklar ortaya konmuştur. Çileklerin biyoaktif özellikleri bakımından Rubygem çeşidinin öne çıktığı, aroma özellikleri bakımından ise üç çeşidin de yakın bileşimlere sahip olduğu ifade edilebilir. Kimyasal özellikleri bakımından Sabrina çeşidi çileklerin daha yüksek şeker kompozisyonu ve asitlik (\%) değerlerine sahip olduğu belirlenmiştir. Bu çalışma ile Florida Fortuna, Sabrina ve Rubygem çilek çeşitlerinin kalite özellikleri ülkemizde ve dünyada yetiştirilen diğer çilek çeşitleri ile karşılaştırılarak sunulmuştur.

\section{EKLER}

Ticari olgunlukta çileklerin hasadını ve teminini sağlayan Tarım ve Orman Bakanlığı Sultanhisar İlçe Müdürlüğüne ve Sultanhisar Ziraat Odası yetkililerine yazarlar olarak teşekkürlerimizi sunarı.

\section{KAYNAKLAR}

Aaby, K., Ekeberg, D. \& Skrede, G. (2007). Characterization of phenolic compounds in strawberry (fragaria $x$ ananassa) fruits by different HPLC detectors and contribution of individual compounds to total antioxidant capacity. Journal of Agricultural and Food Chemistry, 55, 4395-4406.

Aaby, K., Skrede, G. \& Wrolstad, R. E. (2005). Phenolic composition and antioxidant activities in flesh and achenes of strawberries (Fragaria ananassa). Journal of Agricultural and Food Chemistry, 53 (10), 40324040.

Akbulut, M., Çekiç, Ç. \& Ünver, A. (2006). Bazı oktoploid ve diploid çileklerin fitokimyasal özellikleri. Antioksidan kapasitesi ve mineral miktarlarının belirlenmesi. II. Ulusal Üzümsü Meyveler Sempozyumu, pp. 299-303.

Akçay, V. (2014). Farklı azot dozlarının Rubygem ve Florida fortuna çilek çeşitlerinde verim ve meyve kalite kriterleri üzerine etkisi. Adnan Menderes Üniversitesi Fen Bilimleri Enstitüsü Toprak Bilimi ve Bitki Besleme Anabilim Dalı Yüksek Lisans Tezi, Aydın.

Anonim (2017). http://www.uib.org.tr/tr/kbfile/cilek- 
raporu-2017. Erişim tarihi: 28.09.18.

Anttonen, M.J., Hoppula, K.I., Nestby, R., Verheul, M.J. \& Karjalainen, R.O. (2006). Influence of fertilization, mulch color, early forcing, fruit order, planting date, shading, growing environment, and genotype on the contents of selected phenolics in strawberry (Fragaria $x$ ananassa Duch.) fruits. Journal of Agricultural and Food Chemistry, 54, 2614-2620.

Atasay, A. \& Türemiş, N. (2008). Eğirdir (Isparta) koşullarında organik çilek yetiştiriciliğinin uygulanabilirliği üzerine bir araştırma. Çukurova Üniversitesi Fen Bilimleri Enstitüsü Dergisi, 18 (3), 7281.

Basu, A., Nguyen, A., Betts, N.M. \& Lyons, T.J. (2014). Strawberry as a functional food: an evidence-based review. Critical Reviews in Food Science and Nutrition, 54, 790-806.

Buendía, B., Gil, M.I., Tudela, J.A., Gady, A.L., Medina, J.J., Soria, C., López, J.M. \& Tomas-Barberan, F.A. (2010). HPLC-MS analysis of proanthocyanidin oligomers and other phenolics in 15 strawberry cultivars. Journal of Agricultural and Food Chemistry, 58, 3916-3926.

Elik, A., Yanık, D. K. \& Göğüş, F. (2017). Optimization of microwave-assisted extraction of phenolics from organic strawberry using response surface methodology. Harran Tarım ve Gıda Bilimleri Dergisi, 21(2), 143-154.

Grajeda-Iglesias, C., Salas, E., Barouh, N., Barea, B., Panya, A. \& Figueroa-Espinoza, M. C. (2016). Antioxidant activity of protocatechuates evaluated by $\mathrm{DPPH}$, ORAC, and CAT methods. Food Chemistry, 194, 749757.

Günay, S. (2004). Çanakkale Koşullarına Uygun Çilek (Fragaria spp.) Çeşitlerinin belirlenmesi üzerine araştırmalar. Çanakkale Onsekiz Mart Üniversitesi Fen Bilimler Enstitüsü Bahçe Bitkileri Anabilim Dalı Yüksek Lisans Tezi, Çanakkale.

Gündüz, K. \& Özdemir, E. (2012). Çileklerde Meyve Kalite Özellikleri Arasındaki iliş̧kiler. Iğdır Üniversitesi Fen Bilimleri Enstitüsü Dergisi, 2 (1), 9-14.

Hakala, M. A., Lapveteläinen, A. T. \& Kallio, H. P. (2002). Volatile compounds of selected strawberry varieties analyzed by purge-and-trap headspace GCMS. Journal of agricultural and food chemistry, 50 (5), 1133-1142.

Hakala, M., Lapveteläinen, A., Huopalahti, R., Kallio, H. \& Tahvonen, R. (2003). Effects of varieties and cultivation conditions on the composition of strawberries. Journal of Food Composition and Analysis, 16 (1), 67-80.

Jetti, R. R., Yang, E., Kurnianta, A., Finn, C. \& Qian, M. C. (2007). Quantification of selected aroma-active compounds in strawberries by headspace solidphase microextraction gas chromatography and correlation with sensory descriptive analysis. Journal of Food Science, 72 (7), S487-S496.

Kafkas, E., Kafkas, S., Koch-Dean, M., Schwab, W., Larkov, O., Lavid, N., Bar, E., Ravid, U. \& Lewinsohn, E. (2005). Comparison of methodologies for the identification of aroma compounds in strawberry. Turkish Journal of Agriculture and Forestry, 29 (5), 383-390.

Kalt, W., Forney, C. F., Martin, A. \& Prior, R. L. (1999).
Antioxidant capacity, vitamin C, phenolics, and anthocyanins after fresh storage of small fruits. Journal of Agricultural and Food Chemistry, 47 (11), 4638-4644.

Karahan, H., Özsayın, D., \& Karaman, S. (2015). Organik çilek yetiştiriciliği yapan işletmelerin Sosyo-Ekonomik açıdan incelenmesi. Harran Tarım ve Gıda Bilimleri Dergisi, 19(1), 9-15.

Karakaya, M., Öztürk, B., İslam, A., Karakaya, O., Kaçar, E., Turga, E. \& Gün, S. (2015). Ordu ekolojik koşullarında yetiştirilen bazı çilek çeşitlerinin meyve kalite özellikleri. VII. Ulusal Bahçe Bitkileri Kongresi, pp. 2529.

Kaynaş, N. \& Günay, S. (2003). Çanakkale Yöresine Uygun Çilek Çeşitlerinin Saptanması Üzerine Çalışmalar. Ulusal Kivi ve Üzümsü Meyveler Sempozyumu, pp. 230-234, Ordu.

Kim, D. O., Jeong, S. W. \& Lee, C. Y. (2003). Antioxidant capacity of phenolic phytochemicals from various cultivars of plums. Food Chemistry, 81 (3), 321-326.

Koyuncu, M. A. \& Dilmaçünal, T. (2010). Determination of vitamin $C$ and organic acid changes in strawberry by HPLC during cold storage. Notulae Botanicae Horti Agrobotanici Cluj-Napoca, 38 (3), 95-98.

Meyers, K.J., Watkins, C.B., Pritts, M.P. \& Liu, R.H. (2003). Antioxidant and antiproliferative activities of strawberries. Journal of Agricultural and Food Chemistry, 51, 6887-6892.

Nielsen, T. \& Leufvén, A. (2008). The effect of modified atmosphere packaging on the quality of Honeoye and Korona strawberries. Food Chemistry, 107 (3), 1053-1063.

Nuñez-Mancilla, Y., Pérez-Won, M., Uribe, E., Vega-Gálvez, A. \& Di Scala, K. (2013). Osmotic dehydration under high hydrostatic pressure: effects on antioxidant activity, total phenolics compounds, vitamin C and colour of strawberry (Fragaria vesca). LWT-Food Science and Technology, 52 (2), 151-156.

Ornelas-Paz, J. D. J., Yahia E. M., Ramírez-Bustamante, N., Pérez-Martínez, J. D., Escalante-Minakata, M. D. P., Ibarra-Junquera, V., Acosta-Muñiz, C., GuerreroPrieto, V. \& Ochoa-Reyes, E. (2013). Physical attributes and chemical composition of organic strawberry fruit (Fragaria $\mathrm{x}$ ananassa Duch, CV. Albion) at six stages of ripening. Food Chemistry, 138 (1), 372-381.

Öz, A. T. \& Eker, T. (2016). Osmaniye koşullarında yetişen Osmanlı ve Rubygem çilek çeşitlerinin kalite ve fitokimyasal bileşiminin belirlenmesi. Bahçe, 45 (Özel Sayı 2), 195-199.

Özbahçali, G. (2014). Bazı Çilek Çeşitleri (Fragaria $x$ Ananassa Duch.J'nin Erzurum ekolojisindeki performanslarının belirlenmesi. Fen Bilimler Enstitüsü Bahçe Bitkileri Anabilim Dalı Yüksek Lisans Tezi, Erzurum.

Özdemir, E., Gündüz, K. \& Şehitoğlu, M. (2003). Yayladağı (Hatay) koşullarında yetiştirilen bazı çilek çeşitlerinin verim ve kalite özelliklerinin belirlenmesi. Türkiye IV. Ulusal Bahçe Bitkileri Kongresi, pp. 301-302.

Özgüven, Al. \& Yılmaz, C. (2003). Adana ekolojik koşullarında bazı kaliforniya çilek çeşitlerinin adaptasyonu. Ulusal Kivi ve Üzümsü Meyveler Sempozyumu, pp. 208-212, Ordu. 
Özgüven, Al. \& Yılmaz, C. (2009). Bazı çilek çeşitlerinin Adana ekolojik koşullarındaki morfolojik ve pomolojik özellikleri. Alatarım, 8, 17-21.

Pérez-Jimenez, J., Neveu, V., Vos, F. \& Scalbert, A. (2010). Identification of the 100 richest dietary sources of polyphenols: An application of the phenolexplorer database. European Journal of Clinical Nutrition, 64, 112-120.

Pirlak, L. \& Köse, M. (2009). Effects of plant growth promoting rhizobacteria on yield and some fruit properties of strawberry. Journal of Plant Nutrition, 32 (7), 1173-1184.

Pineli, L. D. L. D. O., Moretti, C. L., dos Santos, M. S., Campos, A. B., Brasileiro, A. V., Córdova, A. C. \& Chiarello, M. D. (2011). Antioxidants and other chemical and physical characteristics of two strawberry cultivars at different ripeness stages. Journal of Food Composition and Analysis, 24 (1), 1116.

Proteggente, A.R., Pannala, A.S., Paganga, G., Van Buren, L., Wagner, E., Wiseman, S., Van De Put, F., Dacombe, C. \& Rice-Evans, C.A. (2002). The antioxidant activity of regularly consumed fruit and vegetables reflects their phenolic and vitamin c composition. Free Radical Research, 36, 217-233.

Sandhu, A. K., Miller, M. G., Thangthaeng, N., Scott, T. M., Shukitt-Hale, B., Edirisinghe, I. \& Burton-Freeman, B. (2018). Metabolic fate of strawberry polyphenols after chronic intake in healthy older adults. Food \& Function, 9 (1), 96-106.

Sarkis, J. R., Michel, I., Tessaro, I. C. \& Marczak, L. D. F. (2014). Optimization of phenolics extraction from sesame seed cake. Separation and Purification Technology, 122, 506-514.

Shrestha, N., Shrestha, S. \& Bhattarai, A. (2016).
Determination of ascorbic acid in different citrus fruits of Kathmandu Valley. Journal of Medical and Biological Science Research, 2, 9-14.

Stavang, J.A., Feritag, S., Foito, A., Verrall, S., Heide O.M., Stewart, D. \& Sønsteby, A. (2015). Raspberry fruit quality changes during ripening and storage as assessed by colour, sensory evaluation and chemical analyses. Scientia Horticulturae, 195, 216-225.

Strålsjö, L.M., Witthöft, C.M., Sjöholm, I.M. \& Jägerstad, M.I. (2003). Folate content in strawberries (Fragaria $x$ ananassa): Effects of cultivar, ripeness, year of harvest, storage, and commercial processing. Journal of Agricultural and Food Chemistry, 51, 128-133.

TÜiK. (2016). www.tuik.gov.tr. Erişim tarihi: 28.09.18.

Wang, S.Y. \& Millner, P. (2009). Effect of different cultural systems on antioxidant capacity, phenolic content, and fruit quality of strawberries (Fragaria $x$ aranassa Duch.). Journal of Agricultural and Food Chemistry, 57, 9651-9657.

Wang, S. Y. \& Lin, H. S. (2000). Antioxidant activity in fruits and leaves of blackberry, raspberry, and strawberry varies with cultivar and developmental stage. Journal of Agricultural and Food Chemistry, 48 (2), 140-146.

Wojdylo, A., Figiel, A. \& Oszmianski, J. (2009). Effect of drying methods with the application of vacuum microwaves on the bioactive compounds, color, and antioxidant activity of strawberry fruits. Journal of Agricultural and Food Chemistry, 57, 1337-1343.

Yildiz, H., Ercisli, S., Hegedus, A., Akbulut, M., Topdas, E.F. \& Aliman, J. (2014). Bioactive content and antioxidant characteristics of wild (Fragaria vesca L.) and cultivated strawberry (Fragaria $\times$ ananassa Duch.) fruits from Turkey. Journal of Applied Botany and Food Quality, 87 (1), 274-278. 